\title{
Study on the Temperature of the Bridge Wire in the Initiator Used in Nuclear Explosion Valve
}

\author{
Lan Shi, An-Min Yang, Ying-Chun Zhang, Yuan-He Wang, Zhanying Li \\ Shaanxi Applied Physics-Chemistry Research Institute, Xi'an, China \\ Email: 996186603@qq.com
}

How to cite this paper: Shi, L., Yang, A.-M., Zhang, Y.-C., Wang, Y.-H. and Li, Z. (2016) Study on the Temperature of the Bridge Wire in the Initiator Used in Nuclear Explosion Valve. American Journal of Analytical Chemistry, 7, 908-917.

http://dx.doi.org/10.4236/ajac.2016.712077

Received: November 5, 2016

Accepted: December 19, 2016

Published: December 22, 2016

Copyright $\odot 2016$ by authors and Scientific Research Publishing Inc. This work is licensed under the Creative Commons Attribution International License (CC BY 4.0).

http://creativecommons.org/licenses/by/4.0/

\begin{abstract}
This paper established the mathematical model of bridge wire temperature rise under direct current condition and gave the solution. It computed bridge wire temperature by using the thermal-electric coupling method provided by ANSYS-Workbench finite element analysis software. In the end, the temperature bridge wire applied to different electric current was measured by the infrared thermal imaging temperature measurement method. The result shows that the ANSYS simulation results are in agreement with the theoretical calculation and the experimental results. It is feasible to compute bridge wire temperature of initiator by using ANSYS-Workbench software, and it is an important method to analyze complex structure of pyrotechnics.
\end{abstract}

\section{Keywords}

Bridge Wire Temperature, ANSYS-Workbench Thermal-Electric Coupling, Infrared Thermal Imaging

\section{Introduction}

Electric explosive devices (hereinafter short for EED) are widely used in aerospace, weapons and equipment [1] civil blasting and other fields because of their short reaction time and high reliability, safety, stable performance [2]. Among them, the bridge wire electrical initiator is a more widely used one. The reaction of bridge wire electrical initiator can be described as: bridge wire receives electric power (usually in two forms of capacitance and DC), then turns the electric into heat, and transfers the heat to the powder, when the temperature reaches to the powder's explosive point, the initiator works [3].

Wang Kai-min et al. [4], respectively, derived the safety current formulas of bridge wire initiator, but the formulas did not take into account the external heat loss of the bridge. Cao Jian-hua et al. [5] gave a cylindrical heat transfer model of the bridge wire 
electric explosive devices, presented the energy-balance equation for calculating sensitivity and theoretical calculation method of the input reliability design. However, the heat transfer model doesn't just suit all of the bridge wire EED. Because of the complicated heat transfer among the bridge and the power, the bridge and the ceramic, the temperature rise mathematical model of electric bridge is difficult to establish. In recent years, there have been many domestic and international scholars studied the bridge temperature rise of bridge type EED using simulation software, such as Wang Dao-you et al. [6], Xu Yi-gen et al. [7], Wang Pei-lan et al. [8] and G. R. Peevy et al. [9]. These scholars have proved that the simulation method can be used to study the temperature rise of bridge wire.

The initiator reliability depends on the match of energy and heat dissipation design of the ignition unit, which is mainly formed by the bridge, ceramic and power. Based on ANSYS-Workbench software, the thermal simulation experiment is carried out by using the infrared thermal imaging method, and the temperature of the electrical initiator is analyzed. The Bridge temperature rise research carried out is of great significance to improve the ignition reliability of electrical initiator.

\section{Mathematical Model and Theoretical Calculation}

The temperature rise of the electrical initiator bridge can be described as: the bridge converts electrical energy into heat energy and gradually heats up, this part of the process obeys the Joule-Lenz law; and the bridge transfers the heat to the ceramic and air at the same time. When the energy input to the bridge is equal to the heat dissipated to the outside, the bridge temperature rise process reaches the thermal equilibrium.

Neglect the axial heat transfer of the bridge [10], according to the principle of energy conservation, when the bridge reaches equilibrium:

$$
I^{2} R=\lambda D\left(T-T_{1}\right)+\gamma d\left(T_{1}-T_{0}\right)+h S\left(T-T_{0}\right) .
$$

The left side of the equation is for the external input power; the right side of the first loop is for the thermal conductivity of the insulation rate; the second is the shell thermal conductivity rate; and the third is the rate of air heat dissipation.

The heat transfer between the ceramic and the shell heat transfer layer is equal when the heat transfer is stable:

$$
\lambda D\left(T-T_{1}\right)=\gamma d\left(T_{1}-T_{0}\right) .
$$

By combining the Equations (2.1) and (2.2), we can obtain the temperature $T$ of the bridge under different input current $I$.

$D=1 \times 10^{-3} \mathrm{~m} ; d=2 \times 10^{-3} \mathrm{~m} ; d=1 \times 10^{-3} \mathrm{~m} ; R=1 \Omega ; \lambda=1.3 \mathrm{~W} /(\mathrm{m} \cdot \mathrm{K}) ; \gamma=16.3$ $\mathrm{W} /(\mathrm{m} \cdot \mathrm{K}) 3 \mathrm{~m} ; S=2 \pi r l=3.822 \times 10^{-7} \mathrm{~m}^{2}$; and $T_{0}=28^{\circ} \mathrm{C}$.

When the input current are $0.2 \mathrm{~A}, 0.3 \mathrm{~A}, 0.4 \mathrm{~A}, 0.5 \mathrm{~A}, 0.6 \mathrm{~A}$ and $0.7 \mathrm{~A}$; the calculation results of bridge thermal equilibrium temperature are in Table 1.

\section{Simulation Analysis}

ANSYS software has rich and perfect unit library, material model library and solver. 
Table 1. The temperature of bridge wire under different input current during heat balance.

\begin{tabular}{ccccccc}
\hline Input Current I/(A) & 0.2 & 0.3 & 0.4 & 0.5 & 0.6 & 0.7 \\
\hline $\begin{array}{c}\text { Bridge wire electric heating } \\
\text { temperature } \mathrm{T} /\left({ }^{\circ} \mathrm{C}\right)\end{array}$ & 45.8 & 68.0 & 99.1 & 139.0 & 187.9 & 245.6 \\
\hline
\end{tabular}

With perfect before and after treatment and powerful interface, it can efficiently solve various types of structure static, dynamic, vibration, linear and nonlinear, modal analysis, harmonic response analysis, transient dynamic analysis, fracture mechanics and other issues [11]. In addition, the software can also be coupled to different physical field analysis [12], so it has a widely application in many areas of engineering design. The finite element analysis software is used to simulate the temperature rise process of the electrical initiator bridge. It can predict the ignition current of the electrical initiator, assist the engineering design and performance analysis, and save the design cost and improve the work efficiency.

In this paper, ANSYS-Workbench finite element analysis software sequential electrothermal coupling method is used to analyze the electric-thermal coupling field of the electric-ignition temperature rise process of the electrical initiator bridge. The sequential coupling module is shown in Figure 1.

\subsection{Definition of Material Properties}

Add the required materials and set the required material properties in the ANSYSWorkbench material library. Electrical initiator components of the ignition properties of the components in this article are as follows (Table 2).

\subsection{Geometric Models and Meshing}

In order to simulate the heating condition of the electrical initiator, the geometric model of the igniter assembly of the electric igniter was established by Pro/Engineer (Figure 2), in which the shell, ceramic, pin and bridge wire adopt the solid model.

In the finite element modeling process, the shell and the bridge are modeled using an 8-node 6-faceted element and the rest with a tetrahedral element. The finite element model of the igniter is shown in Figure 3.

\subsection{Load and Boundary Conditions}

In the electrical analysis, constant current load is added between the two pins. The phase angles $0^{\circ}$ and $180^{\circ}$ indicate input and output. The current size is in turn set to $0.2 \mathrm{~A}, 0.3 \mathrm{~A}, 0.4 \mathrm{~A}, 0.5 \mathrm{~A}, 0.6 \mathrm{~A}$ and $0.7 \mathrm{~A}$. In the thermal analysis, the initial ambient temperature is set at $28^{\circ} \mathrm{C}$, the convective heat transfer coefficient between the shell, bridge surface and air is $25 \mathrm{~W} /\left(\mathrm{m}^{2} \cdot{ }^{\circ} \mathrm{C}\right)$, and the rest is adiabatic boundary.

\subsection{ANSYS-Workbench Simulation Results and Analysis}

In the different current, the initiator bridge temperature cloud ( $0.2 \mathrm{~A}$ example) as shown in Figure 4. Bridge temperature simulation results in Table 3. 


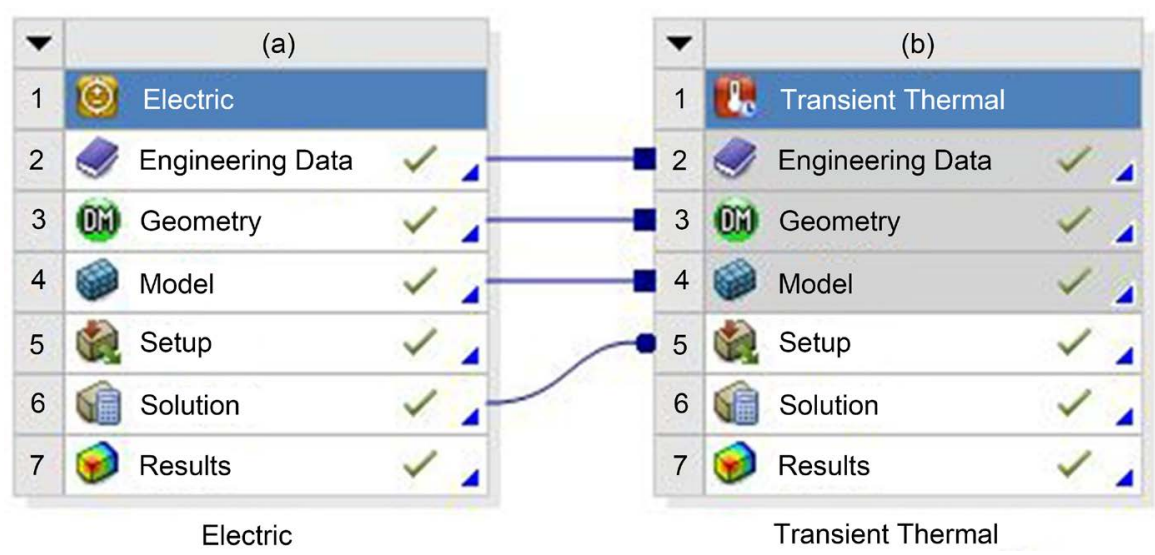

Figure 1. Electro-thermal coupling simulation module.

Table 2. Material parameters of bridge wire.

\begin{tabular}{ccccc}
\hline Parts & Pin & bridge wire & Ceramics & Case \\
\hline Materials & Iron-nickel alloy & $\begin{array}{c}\text { Nickel-chromium } \\
\text { alloy }\end{array}$ & Aluminosilicate & stainless steel \\
$\begin{array}{c}\text { Density }\left(\mathrm{g} / \mathrm{cm}^{3}\right) \\
\begin{array}{c}\text { Thermal Conductivity } \\
\left(\mathrm{W} / \mathrm{m} \cdot{ }^{\circ} \mathrm{C}\right)\end{array}\end{array}$ & 8.21 & 8.3 & 2.4 & 7.86 \\
$\begin{array}{c}\text { Heat capacity } \\
\left(\mathrm{J} / \mathrm{g} \cdot{ }^{\circ} \mathrm{C}\right)\end{array}$ & 16.7 & 16.5 & $1.3 \mathrm{ARE}$ & 16.3 \\
$\nabla$ Resistivity $(\mu \Omega \cdot \mathrm{m})$ & 0.502 & 0.46 & -- & 0.50 \\
\hline
\end{tabular}

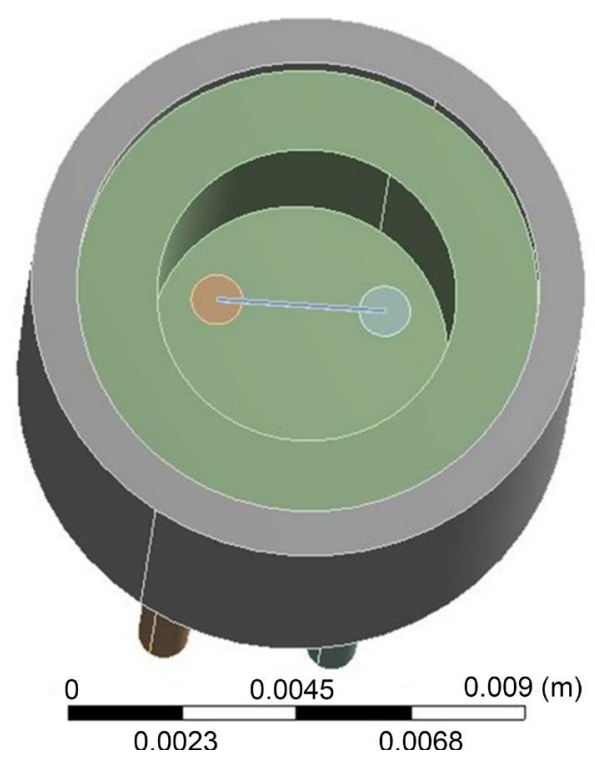

Figure 2. Geometric model.

\section{Experimental Study}

\subsection{The Bridge Wire Temperature Testing}

All objects with temperature above the absolute zero emit infrared radiation energy to 


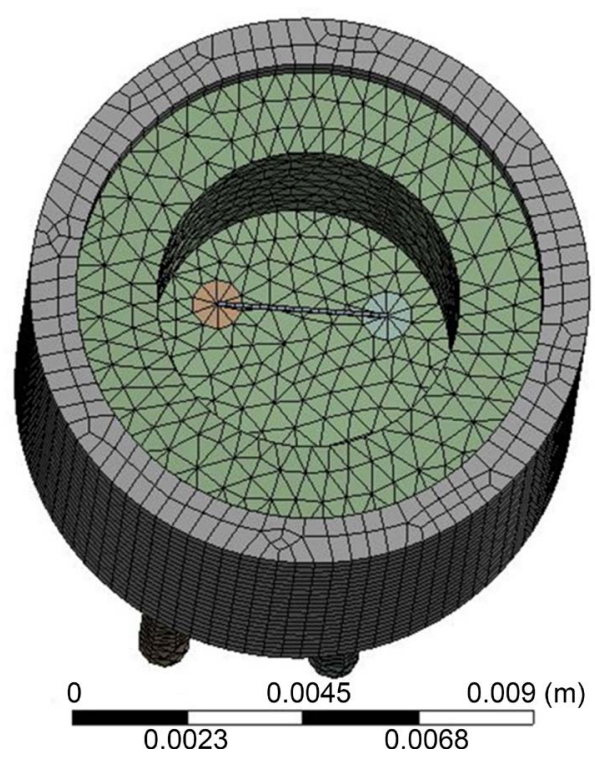

Figure 3. Finite element model.

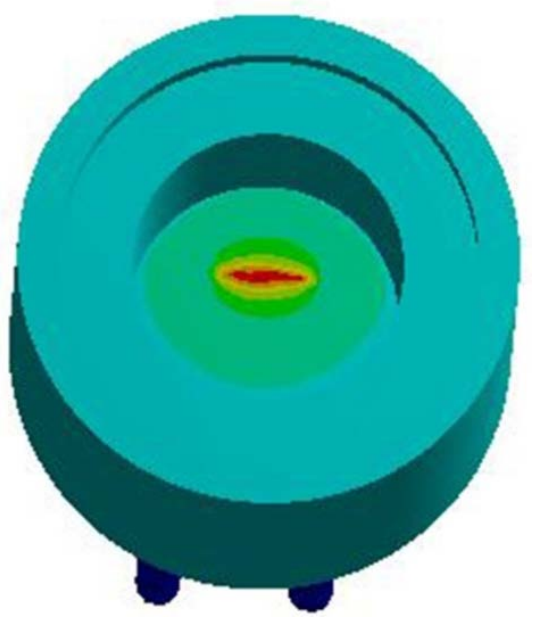

Figure 4. The temperature contour of the bridge wire.

Table 3. The temperature of bridge wire.

\begin{tabular}{ccccccc}
\hline Input Current I/(A) & 0.2 & 0.3 & 0.4 & 0.5 & 0.6 & 0.7 \\
\hline $\begin{array}{c}\text { Bridge wire } \\
\left.\text { temperature } \mathrm{T} /{ }^{\circ} \mathrm{C}\right)\end{array}$ & 44.2 & 65.9 & 96.2 & 137.2 & 183.0 & 239.3 \\
\hline
\end{tabular}

the environment. The infrared radiation energy and wavelength distribution of the object have close relations with its surface temperature. Therefore, by measuring the infrared radiation of the object itself, we can accurately determine its surface temperature, which is infrared radiation based on the objective basis of temperature measurement [13] [14] [15] [16].

In this paper, FLIR SC3000 infrared thermal imaging tester is used for measuring the bridge temperature $(0.5 \mathrm{~A}$ as an example). Temperature distribution at different loca- 
tions and heating curve of the bridge wire under different currents are shown in Figures 5-7 (take the 5A for example, the resolution is 9.2).

The temperature of bridge wire during electric-heat balance at different input currents is shown in Table 4.

\subsection{Data Analysis}

Comparison of theoretical calculation, simulation and experimental results is shown in Table 5 and Figure 8.

ANSYS-Workbench finite element analysis software simulation and test results $(0.5 \mathrm{~A}$ example) for the comparison are shown in Figure 9.

From the comparison of theoretical calculation, simulation and experimental results, we can see that the results are similar. The temperature of bridge wire increases as the input current increases. The temperature of the middle part is higher than both ends of the bridge. The result of the bridge temperature rise is more intuitive using the simulation analysis method.

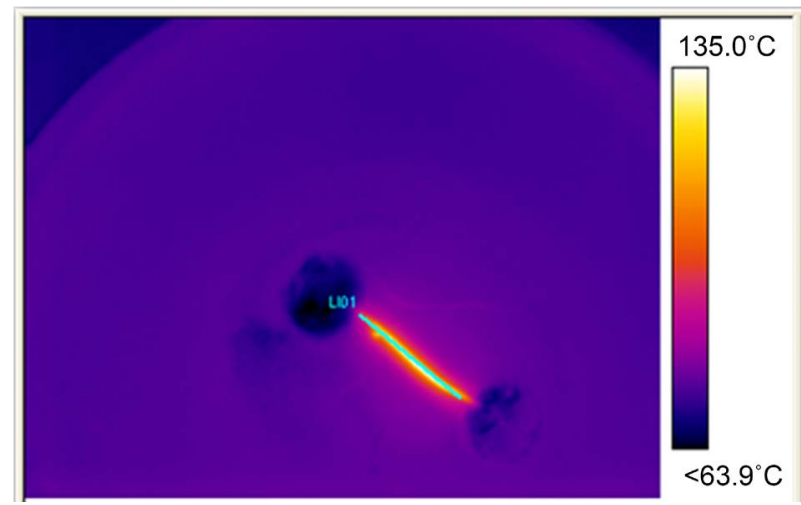

Figure 5. The thermal state of the bridge wire after electrified.

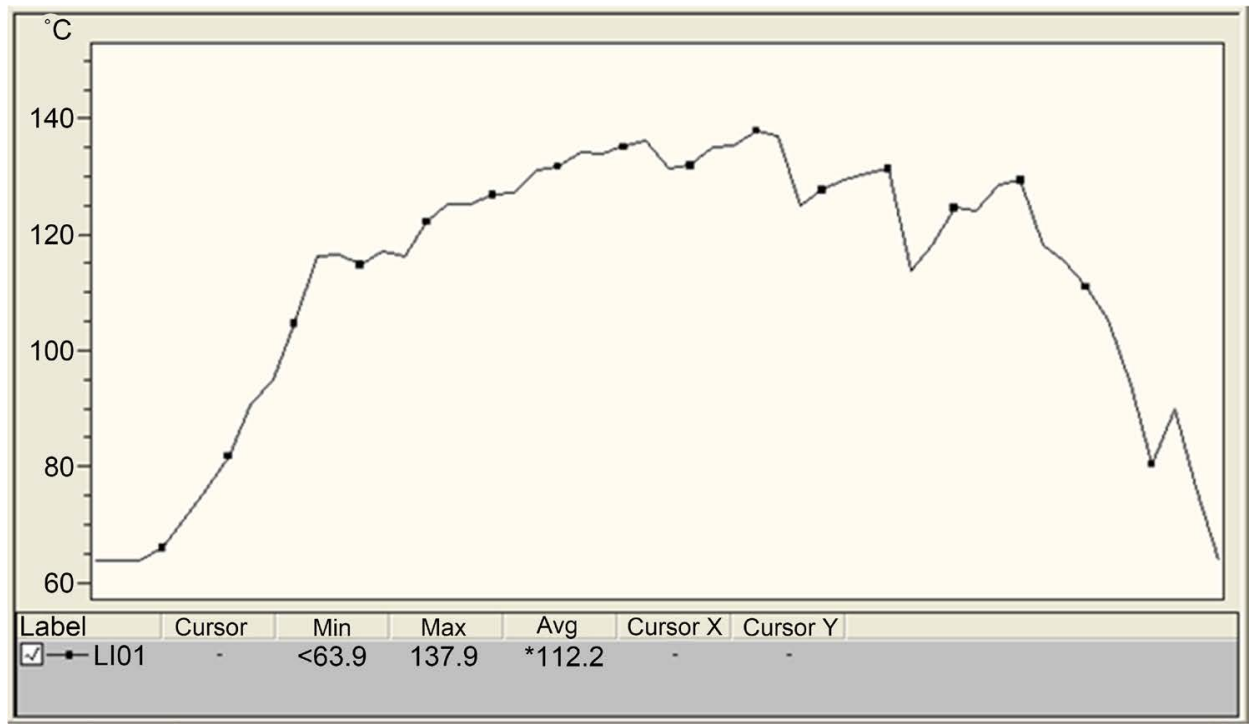

Figure 6. The thermal state in different locations of the bridge wire after electrified. 


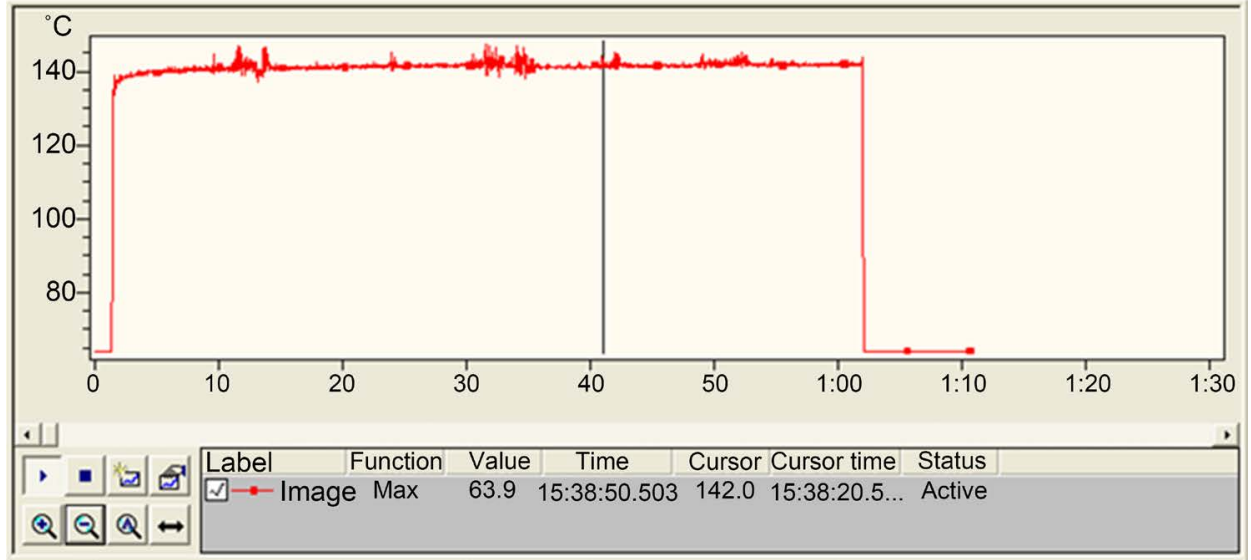

Figure 7. Temperature curve of the bridge wire after electrified.

Table 4. The temperature of bridge wire during electric-heat balance.

\begin{tabular}{ccccccc}
\hline $\begin{array}{c}\text { Input Current } \\
\mathrm{I} /(\mathrm{A})\end{array}$ & 0.2 & 0.3 & 0.4 & 0.5 & 0.6 & 0.7 \\
\hline $\begin{array}{c}\text { Bridge wire temperature } \\
\mathrm{T} /\left({ }^{\circ} \mathrm{C}\right)\end{array}$ & 43.0 & 65.8 & 99.7 & 142.0 & 188.2 & 232.5 \\
\hline
\end{tabular}

Table 5. Comparison of theoretical calculation, simulation and experimental results.

\begin{tabular}{|c|c|c|c|c|c|}
\hline \multirow[b]{2}{*}{$\begin{array}{c}\text { Input } \\
\text { Current }\end{array}$} & \multirow[b]{2}{*}{$\begin{array}{l}\text { Theoretical } \\
\text { calculation }\end{array}$} & \multirow[b]{2}{*}{$\begin{array}{l}\text { Simulation } \\
\text { calculation }\end{array}$} & \multirow[b]{2}{*}{ experiment } & \multicolumn{2}{|c|}{ deviation } \\
\hline & & & & $\begin{array}{l}\text { Theory and } \\
\text { Simulation }\end{array}$ & $\begin{array}{l}\text { Experiment } \\
\text { and } \\
\text { Simulation }\end{array}$ \\
\hline $0.2 \mathrm{~A}$ & $45.8^{\circ} \mathrm{C}$ & $44.2^{\circ} \mathrm{C}$ & $43.0^{\circ} \mathrm{C}$ & $3.49 \%$ & $2.71 \%$ \\
\hline $0.3 \mathrm{~A}$ & $68.0^{\circ} \mathrm{C}$ & $65.9^{\circ} \mathrm{C}$ & $65.8^{\circ} \mathrm{C}$ & $3.09 \%$ & $0.15 \%$ \\
\hline $0.4 \mathrm{~A}$ & $99.1^{\circ} \mathrm{C}$ & $96.2^{\circ} \mathrm{C}$ & $99.7^{\circ} \mathrm{C}$ & $2.93 \%$ & $3.51 \%$ \\
\hline $0.5 \mathrm{~A}$ & $139.0^{\circ} \mathrm{C}$ & $137.2^{\circ} \mathrm{C}$ & $142.0^{\circ} \mathrm{C}$ & $1.29 \%$ & $3.38 \%$ \\
\hline $0.6 \mathrm{~A}$ & $187.9^{\circ} \mathrm{C}$ & $183.0^{\circ} \mathrm{C}$ & $188.2^{\circ} \mathrm{C}$ & $2.61 \%$ & $2.76 \%$ \\
\hline $0.7 \mathrm{~A}$ & $245.6^{\circ} \mathrm{C}$ & $239.3^{\circ} \mathrm{C}$ & $232.5^{\circ} \mathrm{C}$ & $2.57 \%$ & $2.84 \%$ \\
\hline
\end{tabular}

At the same time, compared with the theoretical calculation (rely on a large number of tests), the design costs will reduce, the design efficiency will improve and the product development cycle will speed up by using the simulation analysis method.

\section{Conclusion and Outlook}

\subsection{Conclusions}

Through the theoretical analysis, simulation calculation and temperature test of the bridge, the following conclusions can be drawn:

(1) Due to the cooling effect, when the current input, the temperature of the middle part is higher than both ends of the bridge.

(2) The simulation results show that the error between the theoretical results and the 


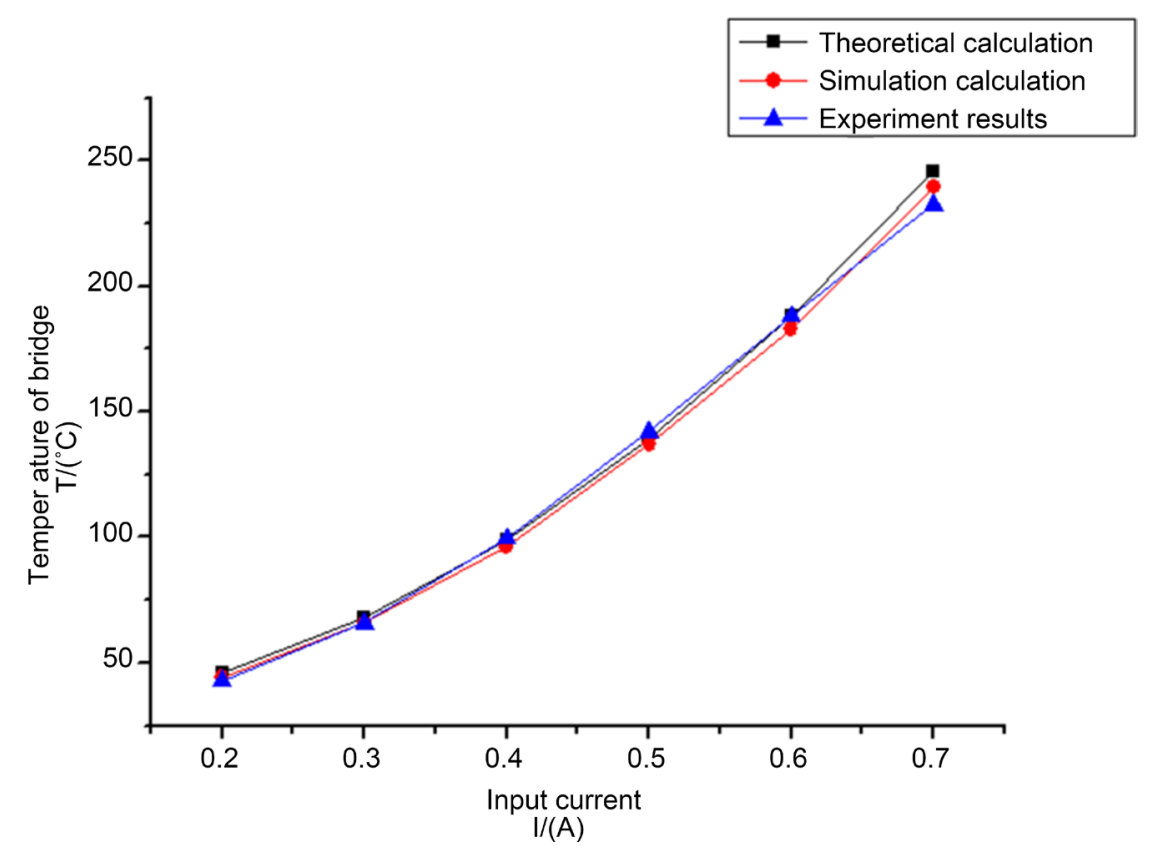

Figure 8. Comparison of theoretical calculation, simulation and experimental results.

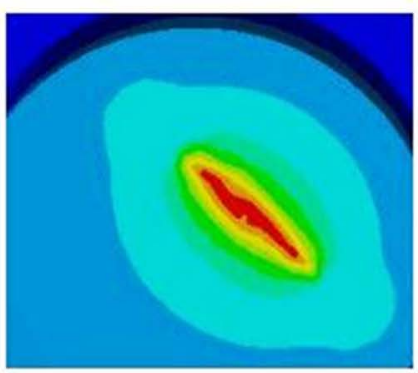

(a)

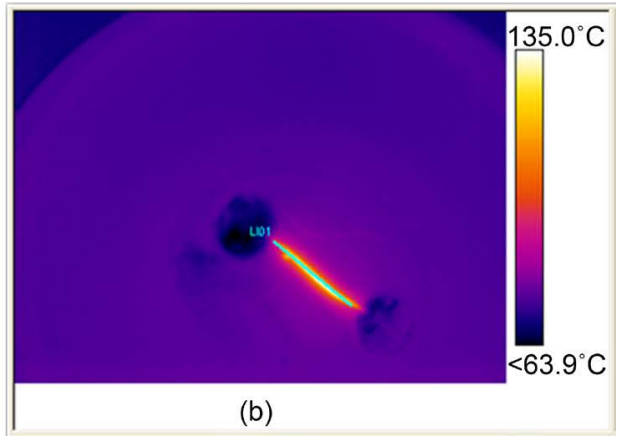

(b)

Figure 9. Comparison of simulation and experimental result of the temperature distribution of bridge. (a) Simulation result; (b) Experimental result.

experimental results is less than $4 \%$. The simulation can accurately simulate the temperature rise after the bridge is powered on.

(3) Compared with the theoretical calculation, the detailed temperature distribution information of the model can be obtained by using the ANSYS-Workbench electrothermal coupling method, and the complex and accurate mathematical model can be calculated.

\subsection{Outlook}

In this paper, the theoretical calculation, simulation calculation and infrared temperature measurement on the temperature rise of the bridge are carried out. The results show that the ANSYS-Workbench finite element software can be used to calculate the electrical initiator bridge temperature rise. The author will use this analysis method to analyze the bridge temperature rise under different current, bridge shape and different 
materials (ceramic, power) of initiator firing unit, and propose a method to optimize the electrical initiator unit in order to improve the reliability of electrical initiator products, reduce the design costs and speed up the product development cycle.

\section{References}

[1] Li, G.-X., Cheng, G.-Y. and Jiao, Q.-J. (1998) Experiment and Test Technology of Initiating Explosive Device. Beijing Institute of Technology University Press, Beijing.

[2] Cai, R.-J. (1999) Engineering Design Principle of Explosive Device. Beijing Institute of Technology University Press, Beijing.

[3] Chen, F.-M. (1990) Pyrotechnics' Principle and Design. Weapons Industry Press, Beijing.

[4] Wang, K.-M. and Wen, Q.-Y. (2006) Design Technology of Military Pyrotechnics. National Defense Industry Press, Beijing.

[5] Cao, J.H., Cai, R.J., Dong, H.P. and Li, Y.Q. (2004) The Temperature Rising Models of Bridge Wire and Explosive of Electro-Explosive Device and Application in Reliability Design. Explosive and Shock Waves, 24, 90-95.

[6] Wang, D.-Y. and Hu, X.-X. (1979) Initiating Mathematics-Physics Model of Hot Bridge Wire Electric Initiating Explosive Device. Symposium on the First Academic of the Chinese Ordnance Society, Xi'an, 1-25.

[7] Xu, Y.-G., Wei, G.-H. and Liu, S.-H. (1997) Electrostatic Initiating Mathematics-Physics Model of Hot Bridge Wire Electric Initiating Explosive Device. Acta Armamentarii, 1997, 48-51.

[8] Wang, P.-L., Zeng, X.-Z. and Zhang, S.-Z. (1994) Numerical Simulation of Bridge Wire Temperature of Hot Bridge Wire Explosive Initiator. Symposium on Firework Conference, Xi'an, 66-70.

[9] Furnberg, C.M., Peevy, G.R., Brigham, W.P. and Lyons, G.R. (1995) Computer Modeling of Electrical Performance of Detonators. AIAA/SAE/ASME Joint Propulsion Conference and Exhibit, San Diego, 10-12 July 1995.

[10] Xu, Y.-G., Wei, G.-H. and Liu, S.-H. (1997) The Mathematical Model of Electrostatic Ignition of Scorching Bridle Wire Electro-Explosive. Acta Armamentarii, 1997, 48-51.

[11] Zhang, S.-M. (2003) Structural Analysis Based on Finite Element Software ANSYS7.0. Tsinghua University Press, Beijing.

[12] Wang, Y.-X. (2006) Analysis and Application of Coupling Field in ANSYS Software. YunNan Water Power, 4.

[13] Zeng, Q., Shu, F.-Y. and Liu, Q.-H. (2007) The Working Principle and Application of Infrared Thermometer. Electronics Quality, 2007, 25-26.

[14] Yang, H.-Y. (2015) The Development of Wireless Infrared Temperature Measurement System. Master's Thesis, Central South University of Forestry \& Technology, Changsha.

[15] Zhang, X.L., Liu, Y., Wang, J., Zhou, H. and Sun, Q. (2014) Infrared Thermometry Technology with Different Nonuniformity Correction Temperatures. Chinese Optics, 7, 150-155.

[16] Chen, L., Tang, Z. and Cui, H.-Y. (2013) The Realization of Infrared Thermometric Techniques of Electric Equipment. Electrical Measurement \& Instrumentation, 60. 


\section{Nomenclature}

$I=$ input current $(\mathrm{A})$;

$R=$ bridge resistance $(\Omega)$;

$\lambda=$ ceramic thermal conductivity $\left(\mathrm{W} \cdot \mathrm{m}^{-1} \cdot{ }^{\circ} \mathrm{C}^{-1}\right)$;

$h=$ convective heat transfer coefficient of air $\left(\mathrm{W} \cdot \mathrm{m}^{-2} \cdot{ }^{\circ} \mathrm{C}^{-1}\right)$;

$D=$ ceramic heat transfer thickness $(\mathrm{m})$;

$d=$ shell thickness $(\mathrm{m})$;

$S=$ convection heat transfer area $\left(\mathrm{m}^{2}\right)$;

$r=$ radius of bridge $(\mathrm{m})$;

$I=$ length of bridge $(\mathrm{m})$;

$T=$ bridge thermal equilibrium temperature $\left({ }^{\circ} \mathrm{C}\right)$;

$T_{1}=$ temperature of the surface which ceramic in contact with the shell $\left({ }^{\circ} \mathrm{C}\right)$;

$T_{0}=$ initial ambient temperature $\left({ }^{\circ} \mathrm{C}\right)$.

Submit or recommend next manuscript to SCIRP and we will provide best service for you:

Accepting pre-submission inquiries through Email, Facebook, LinkedIn, Twitter, etc. A wide selection of journals (inclusive of 9 subjects, more than 200 journals)

Providing 24-hour high-quality service

User-friendly online submission system

Fair and swift peer-review system

Efficient typesetting and proofreading procedure

Display of the result of downloads and visits, as well as the number of cited articles

Maximum dissemination of your research work

Submit your manuscript at: http://papersubmission.scirp.org/

Or contact ajac@scirp.org 